\title{
AVALIAÇÃO DE IDADES DE DESMAME E MANEJO ALIMENTAR DE LEITÕES EM SISCAL
}

\section{Weaning Age and Nutritional Diets for Outdoors Piglets}

\author{
Luiz Alexandre Filho ${ }^{1}$ \\ Renato Irgang ${ }^{2}$ \\ Marília T. S. Padilha ${ }^{3}$ \\ Alciony Andréia da Cunha Alexandre ${ }^{4}$ \\ Sabino Leonides Moteka ${ }^{5}$
}

\section{Resumo}

Este trabalho teve como objetivo avaliar duas idades de desmame: uma precoce, dos 19 aos 23 dias de idade, e outra tardia, dos 28 aos 34 dias de idade; e duas dietas nutricionais, uma simples e outra mais complexa, composta pelas rações pré-inicial, inicial-1 e inicial-2, em leitões em Sistema Intensivo de Suínos Criados ao Ar Livre (SISCAL). Foram utilizados 64 leitões machos castrados e 64 fêmeas. Os leitões foram avaliados em dois períodos, sendo a primeira fase do desmame aos 35 dias de idade e a segunda fase dos 36 aos 49 dias de vida. O experimento foi desenvolvido na Fazenda Experimental da UFSC. Na primeira fase, considerada crítica, os leitões desmamados precocemente com dieta simples apresentaram melhor desempenho produtivo, que foi confirmado na segunda fase. Os resultados mostraram que leitões em SISCAL, na fase de creche, do desmame aos 49 dias de vida, apresentam excelente desempenho quando desmamados aos 21 aos 23 dias de idade e alimentados com dietas simples, alcançando o peso exigido para o repasse aos produtores terminadores.

Palavras-chave: Desmame; Dietas; SISCAL; Suínos.

\section{Abstract}

The objective of this work was to evaluate the effect of two weaning ages: an early age, between 19 and 23, and a later age, between 28 and 34 days, and of two nutritional diets, a simple and a more complex one, with three rations: pre-initial, initial-1 and initial-2, on the performance of piglets raised outdoors. A total of 64 castrated males and 64 females were used in the experiment. The piglets were evaluated in two phases: from weaning up to 35 days, and from 36 up to 49 days of age. The experiment was run at the Fazenda da Ressacada, Universidade Federal de Santa Catarina, Florianopolis, SC, Brazil. Piglets weaned earlier and fed the simple diet presented better performance in both phases, leading to the conclusion that piglets raised outdoor, from weaning up to 49 days age, can be early weaned and can be fed simple and less expensive diets in order to attain the necessary weight to be transferred to finishing hog producers.

Keywords: Diets; Outdoor system; Swine; Weaning age.

1 Doutorando do CRN/UEM, Pesquisador, Rua Antônio Gonçalves, 608. CEP 87890-000

Terra Rica - PR. e-mail: luizalefilho@bol.com.br alecunha@terrarica.net

2 Doutor da UFSC, Professor Pesquisador.

3 Doutora da UFSC, Professora pesquisadora.

4 MSc do CRN/UEM, Pesquisadora.

5 MSc do CRN/UEM, Pesquisador. 


\section{Introdução}

O Sistema Intensivo de Suínos Criados ao Ar Livre (SISCAL) apresenta-se como alternativa ao sistema confinado e é compatível com o bemestar e com a saúde dos animais e, quando bem manejado, é positivo do ponto de vista ambiental. Na suinocultura praticada nos últimos 30 anos, desenvolvida em confinamento, passou-se de um período de aleitamento de 40 a 50 dias, para desmames aos 35, 28, 21 dias de idade e, atualmente, para até menos de 21 dias de idade. Em SISCAL o desmame de leitões é feito entre 25 a 35 dias de idade (COSTA; MONTICELLI, 1996).

Revisando-se o manejo alimentar de leitões criados em SISCAL, verificou-se que não diferiu do recomendado para o sistema confinado. Isto significa que a matéria-prima utilizada nas rações, que os aditivos e o manejo alimentar utilizados para animais confinados são iguais aos recomendados para o SISCAL, que proporciona ambiente mais favorável de criação, com maior área por animal e que proporciona uma condição mínima de estresse, com menor impacto de doenças sobre a produtividade, levando o animal a um bom estado de saúde (SESTI; SOBESTIANSKY, 1996).

$O$ presente trabalho teve por objetivo avaliar práticas de manejo de desmame e dietas para leitões criados em SISCAL até os 49 dias de idade, com o intuito de contribuir para o estabelecimento de um sistema sustentável de produção de leitões.

\section{Material e métodos}

Após o desmame, os leitões foram transferidos para os piquetes de creche, que se caracterizaram por disponibilizar $9 \mathrm{~m}^{2}$ por animal. Esses piquetes estavam cercados com telas, tábuas e por um fio de arame eletrificado, a $10 \mathrm{~cm}$ de altura do solo. Para o abrigo dos animais foram utilizadas cabanas móveis, nos quais os leitões permaneceram até os 49 dias de idade, com água e ração à vontade.

No experimento foram avaliadas duas idades diferentes de desmame de leitões, uma de 19 a 23 dias e outra de 28 a 34 dias. Foram utilizados dois manejos alimentares para cada idade de desmame, compostos a partir de três tipos de rações, (pré-inicial, inicial 1 e inicial 2), num total de 04 combinações de tratamentos.
Foram utilizadas oito repetições por combinação de tratamento e quatro leitões por repetição, sendo 02 machos castrados e 02 fêmeas. A fase estudada foi do desmame até os 49 dias de idade. Os animais foram pesados individualmente ao desmame, 35, 49 e 65 dias de idade. As variáveis estudadas foram: o ganho de peso médio diário e total; o consumo médio diário e total de ração; e a conversão da ração consumida em ganho de peso dos leitões.

Foram utilizados 128 leitões produzidos em sistemas de SISCAL Desses, 64 leitões foram desmamados com a idade de 19 a 23 dias e 64 com a idade entre 28 e 34 dias, sendo $50 \%$ fêmeas e $50 \%$ machos castrados. Após o desmame, os leitões foram separados por idade e sexo, pesados individualmente, realizando-se, então, os sorteios para todas as etapas da implantação do experimento.

Na formulação das rações foram utilizados três tipos de núcleos comerciais como fonte de suplemento vitamínico, mineral e de aminoácidos essenciais para suínos em fase inicial. Como fonte de proteínas foi utilizada o farelo de soja, e, como fonte energética, foram utilizados o milho moído e o açúcar, o qual também serviu como palatabilizante. As rações foram assim compostas:

a) Ração Pré-inicial com 25\% de inclusão de núcleo (T-25).

b) Ração Inicial 01 com 15\% de inclusão de núcleo (T-15);

c) Ração inicial 02 com $5 \%$ de inclusão de núcleo (T-05);

Os animais do experimento foram divididos em oito repetições por combinação de tratamento, cada um com 4 leitões, totalizando 32 animais por combinação de tratamento.

Os dois manejos alimentares avaliados no experimento (Tratamentos T-2515 e T-1505) foram utilizados para os leitões desmamados nas duas idades. O tratamento T-2515, considerado como de dieta mais complexa, foi composto pela ração pré-inicial T-25, fornecida aos animais do desmame aos 35 dias de idade, e pela ração inicial 01 T15, fornecida dos 36 aos 49 dias de idade. 0 tratamento (T-1505), considerado com de dieta mais simples, foi composto pelas rações inicial $01 \mathrm{~T}-15$, fornecida aos animais do desmame aos 35 dias de idade, e da ração inicial 02 T-05, fornecida dos 36 aos 49 dias de idade. 
Os dados de peso e de ganho de médio diário e conversão alimentar foram analisados conforme modelo estatístico descrito por Irgang et al. (1992). Para a análise estatística foi utilizado o programa Statistical Analysis System (SAS). As médias foram comparadas de acordo com Snedecor; Cochran (1989).

\section{Resultados e discussão}

Os leitões desmamados precocemente, entre 19 e 23 dias idade, permaneceram no experimento por 28 dias, sendo 14 dias do desmame aos 35 dias de idade, e 14 dias dos 36 aos 49 dias de idade. Os leitões desmamados tardiamente, entre 28 e 34 dias de idade, permaneceram por cinco dias do desmame aos 35 dias de idade, e período igual aos dos leitões desmamados precocemente na fase seguinte do experimento.

Na Tabela 1 são apresentados dados de desempenho dos leitões do desmame aos 35 dias de idade e na Tabela 2, dados de desempenho dos leitões dos 36 aos 49 dias de idade, para a interação idade de desmame e dieta, com as respectivas médias, erro - padrão e comparação de médias.

Verificou-se que os leitões desmamados precocemente, que receberam a dieta do tratamento T-1505, apresentaram maior peso médio aos 35 e 49 dias de idade, diferenciando-se significativamente $(\mathrm{P}<0.05)$ aos 35 dias de idade de todos os outros tratamentos. Aos 49 dias de idade os leitões do T-1505 tiveram desempenho significativamente melhor do que os leitões desmamados tardiamente, que receberam o mesmo tratamento.

A análise do ganho de peso diário (GPD) indicou que até os 35 dias de idade (Tabela 1) houve diferença significativa $(\mathrm{P}<0.05)$ entre as duas idades de desmame e entre os dois tratamentos nutricionais em favor dos animais desmamados tardiamente. Aos 49 dias de idade (Tabela 2), o GPD dos letões desmamados tardiamente e que receberam a dieta T-2515 diferenciou-se significativamente $(\mathrm{P}<0,05)$ do GPD dos leitões desmamados tardiamente e que receberam o tratamento T1505, que teve o menor desempenho.

Os consumos total e médio diário de ração, medidos do desmame aos 35 dias de idade, apresentaram diferença significativa $(\mathrm{P}<0,05)$ diretamente ligada à idade do desmame. $\mathrm{O}$ consumo total foi maior nos leitões desmamados precoce- mente, pelo fato de terem permanecido mais tempo nessa fase, e o consumo médio diário foi maior para os desmamados tardiamente (Tabela 1). Aos 49 dias de idade verificou-se maior consumo total de ração nos leitões desmamados precocemente e que receberam o tratamento $\mathrm{T}-1505$, diferindo significativamente $(\mathrm{P}<0.05)$ dos leitões desmamados tardiamente. A análise do consumo médio diário de ração indicou diferenças significativas $(\mathrm{P}<0,05)$ até os 35 dias de idade entre os leitões do desmame precoce e os do desmame tardio, que receberam o tratamento T-1505. Em relação aos 49 dias de idade, o consumo médio diário de ração diferiu significativamente $(P<0,05)$ entre os leitões do desmame precoce e do tardio para a dieta T1505.

Na conversão alimentar verificou-se diferença significativa $(P<0,05)$ entre os leitões desmamados precocemente, que receberam o tratamento T-1505, e os leitões do desmame tardio, que receberam o tratamento T-2515, tanto aos 35 como aos 49 dias de idade (Tabela 1 e 2), com melhor desempenho para os leitões desmamados tardiamente.

O estresse social dos leitões, com a separação das suas mães, quando desmamados precocemente em SISCAL, segundo Wolf et al. (2002), faz com que passem por um período adaptativo maior do que os leitões desmamados tardiamente, necessitando de mais tempo para normalizarem o consumo de ração do que os desmamados tardiamente, os quais superam essas dificuldades praticamente a partir do primeiro dia pós-desmame consumindo mais ração (Tabela 1). No entanto, os leitões desmamados precocemente apresentaram algum consumo de ração no primeiro dia pós-desmame, que aumenta gradativamente até o terceiro dia de idade e depois tende a se estabilizar.

Isso ocorre, segundo Hotzel (2002), devido ao fato dos leitões, já na fase de aleitamento aos 19 dias de vida quando criados em SISCAL, utilizarem 2,5\% do seu tempo para comer, enquanto que os criados em confinamento gastam apenas 0,2\% de seu tempo para essa mesma atividade. Esse consumo inicial se mostra suficiente para evitar os distúrbios entéricos causados pelos fatores estressantes nutricionais. Em SISCAL os leitões ingerem, além do leite na fase de aleitamento, terra, forragens e ração da mãe, fazendo com que, teoricamente, o seu trato digestivo passe por um processo de adaptação mais lento e gradativo, favorecendo o seu desenvolvimento. 


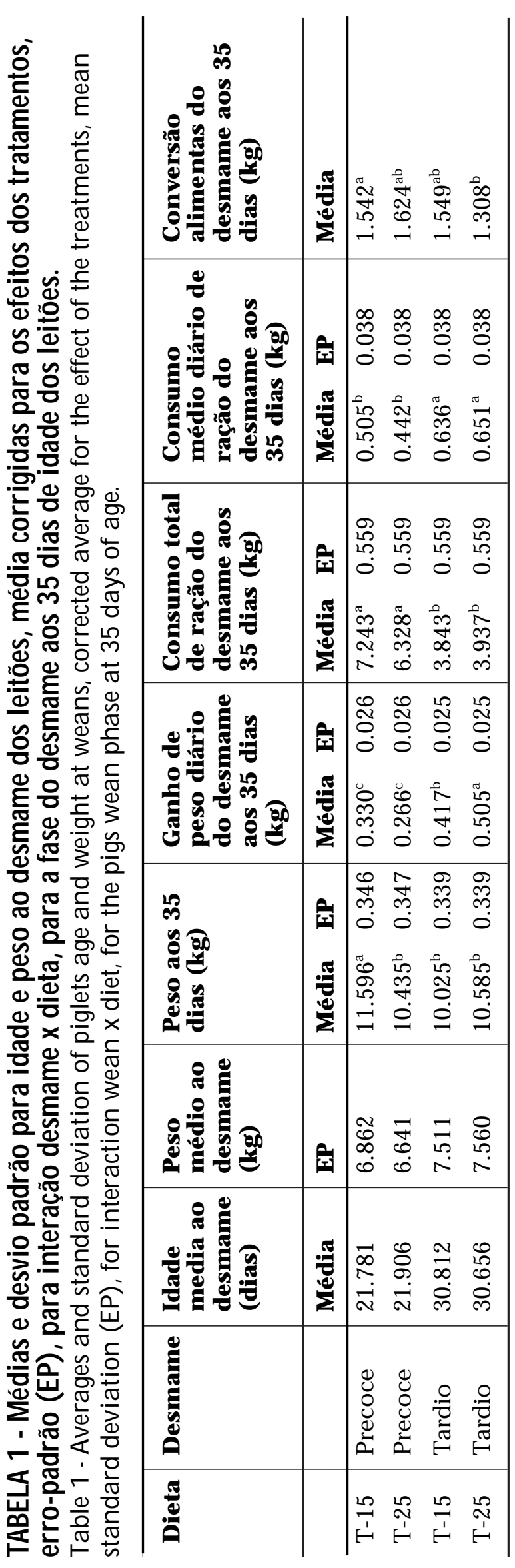

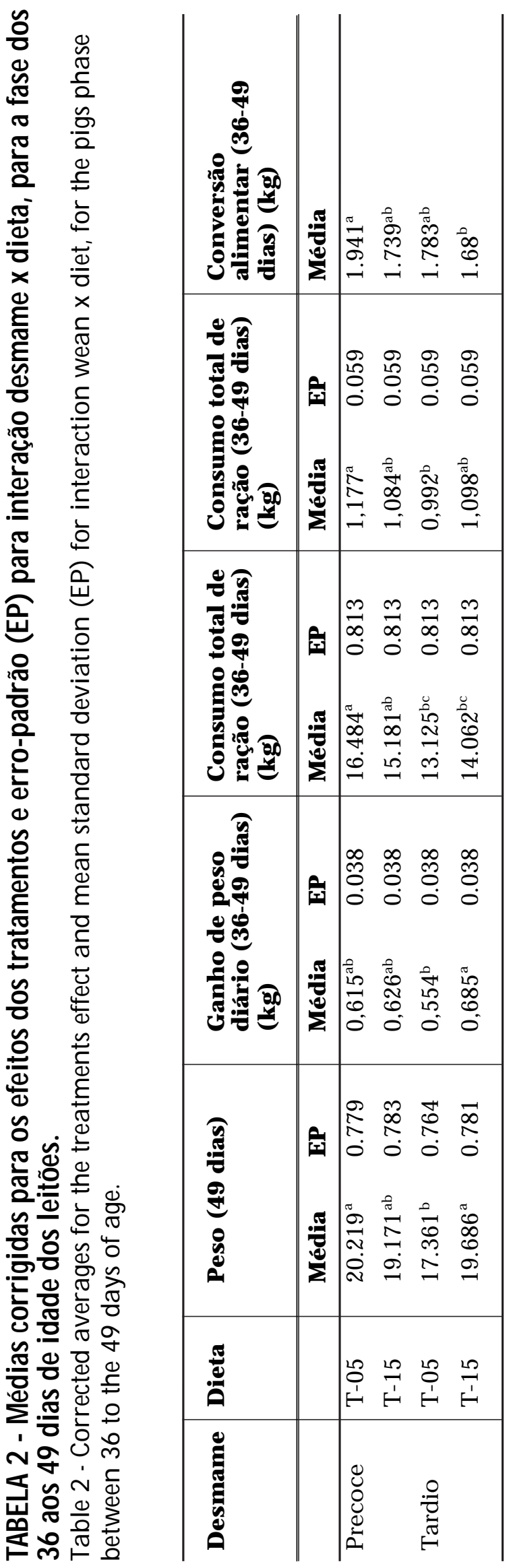




\section{Conclusões}

Em SISCAL pode-se produzir leitões com peso suficiente para atender as exigências de criadores de suínos terminadores. Esses podem ser desmamados precocemente, permanecendo no sistema até os 49 dias de idade com manejo alimentar simples, com rações com 15\% de núcleo, formuladas com produtos de origem animal, que devem ser fornecidas aos leitões durante duas semanas após o desmame, no mínimo.

\section{Referências}

COSTA, O. A. D.; MONTICELU, C. J. Manejo de rotina no sistema intensivo de suínos criados ao ar livre: SISCAL In: SIMPÓ SIO SOBRE SISTEMA INTENSIVO DE SUÍNOS CRIADOS AO AR LIVRE SISCAL, 1., 1996, Concórdia. Anais... Concórdia: EMBRAPA - CNPSA, 1996. p. 221.

HOTZEL, M. J. Mother- offspring interactions in confined and outdoorpigs. NAWAC/ISEConference: Animal Welfare and Behaviour: Fron Science to Solution, 2002. Hamilton, NZ. (no prelo).
IRGANG , R.; SOUZA, J. M.; CARDOSO, S.; SEVERO, J. L P. Desempenho de suínos mestiços criados em confinamento e a campo. R. Soc. Bras. Zoot. v. 21, n. 4, p. 718 - 729, 1992.

SESTI, L.; SOBESTIANSKY, J. Doenças, bioseguridade e manutenção da saúde do plantel. In: SIMPÓSIO SOBRE SISTEMA INTENSIVO DE SUÍNOS CRIADOSAO ARLIVRE - SISCAL, 1., 1996, Concórdia. Anais... Concórdia: EMBRAPA - CNPSA, 1996. p. 221.

SNEDECOR, G. W.; COCHRAN, W. G. Statistical methods. 8. ed. Iowa: Iowa State University Press. 1989.

WOLF, F. M.; HOTEEL, M. J.; MACHADO FILHO , L C. P.; TEIXEIRA, D. L; DINON, P. S. de L; COIMBRA, P. A. D. Influence of age atweaningon behaviom of outdoors raised piglets. $36^{\mathrm{a}}$ International Cangrin of the ISAE 6-10 Ang, 2002. Egmond aan Zee, Holanda.
Recebido em: 16/12/2004

Aprovado em: 30/06/2005 